\title{
Stochastic Finite Element Analysis of Composite Structures with Partially Restrained Connections under Earthquake Loads
}

\author{
Özlem Çavdar \\ Gumushane University \\ Department of Civil \\ Engineering \\ Gümüşhane, Turkey
}

\begin{abstract}
The stochastic analysis of composite structures with partially restrained (PR) connections under seismic loads present some interesting and challenging issues to practicing engineers. This paper proposes an efficient, robust, and accurate method for stochastic finite element analysis of concrete-steel composite structures allowing for PR connections. These are followed by suitable numerical example which indicates that employment of such a stochastic finite element analysis. The Kocaeli earthquake in 1999 is considered as a ground motion. The connections parameters and material properties are random variables. It is essential to properly consider the PR connections in the stochastic dynamic analysis and design of the steel-concrete composite structures since design forces change significantly. The assumption that the connections are rigid, which is routinely used in the application, is not proper. The effect of the variability connection stiffness on the composite structures responses is sufficiently important for consideration in structural safety.
\end{abstract}

Keywords: Stochastic finite element analysis; Composite Structure; PR connections, Stiffness matrix; Monte Carlo simulation.

\section{INTRODUCTION}

This paper presents the effect of the variability in connection stiffness and material (elastic module) properties on stochastic responses of a composite structure modeled with PR beam-tocolumn connections by using stochastic finite element method (SFEM) and Monte Carlo simulation (MCS) method. A computer program for PR connections composite 3-D frame systems was developed in FORTRAN language and incorporated into a general-purpose computer program $[1,10]$ for dynamic deterministic and stochastic analysis of medium and large-scale three-dimensional frames. Then, this program is combined to MCS method. Firstly, the stochastic dynamic analysis results acquired from all the random variables (elastic module and connection rigidities) are compared with each other separately, and secondly the efficiency and accuracy of the proposed are validated by comparison with results of MCS method. Finally, the results of stochastic finite element analyses of the composite structure with fully rigid joints have been compared with the results obtained from two type PR connections. Elastic module and connection rigidities are chosen as random properties. This means these values changes in the borders of a standard deviation. In spite of extensive research into deterministic analysis of PR connections composite construction [2-9], the stochastic dynamic analysis and design of this type of construction form cannot be fully utilized by engineers unless an efficient, robust and accurate method of analysis is available.

\section{Theory}

The stiffness matrix formulation of composite 3-D frames with type PR connections and PSFEM dynamic analysis formulation are given references [10].

\subsection{Stiffness matrix formulation of 3-D composite frame} with PR connections

The stiffness matrix formulation of composite system with type PR connections is given according to References [10-13]. In the stochastic finite element method (SFEM), the deterministic finite element formulation is modified using the perturbation technique or the partial derivative method to incorporate uncertainty in the structural system. Since the basic variables are stochastic, every quantity computed during the deterministic analysis, being a function of the basic variables, is also stochastic. Therefore, the efficient way to arrive at the stochastic response may be to keep account of the stochastic variation of the quantities at every step of the deterministic analysis in terms of the stochastic variation of the basic variables.

There are two fundamental ways to solve the stochastic problem (i) analytical approach and (ii) numerical approach. Among analytical approaches, the perturbation method is widely used because of its simplicity. Numerical method such as Monte Carlo Simulation is generally applicable to all types' stochastic problems and is often used to verify the results obtained from analytical methods. A detailed discussion of these methods is presented below:

\subsection{Perturbation based stochastic finite element method} (PSFEM) formulation

The perturbation method is the most widely used technique for analyzing uncertain system. This method consists of expanding all the random variables of an uncertain system around their respective mean values via Taylor series and deriving analytical expression for the variation of desired response quantities such as natural frequencies and mode shapes of a structure due to small variation of those random variables. The basic idea behind the perturbation method is to express the stiffness and mass matrices and the responses in terms of Taylor series expansion with respect to the parameters centered at the mean values [1].

\subsection{Monte Carlo Method (MCS)}

The Monte Carlo Simulation generates a set of random values of $\mathrm{X}$ according to its probability distribution function. The set 
can be written as $X=\left\{x_{1}, x_{2}, \ldots, x_{N}\right\}$, where $\mathrm{N}$ is the number of simulation. For each values of $X$, the stiffness and mass matrices are computed. At the end of $\mathrm{N}$ simulations, we have a random set of displacement and stress values $\left\{\left\{q_{\beta}\right\}_{1},\left\{q_{\beta}\right\}_{2},\left\{q_{\beta}\right\}_{3}, \ldots,\left\{q_{\beta}\right\}_{N}\right\}$,

$\left\{\{\sigma\}_{1},\{\sigma\}_{2},\{\sigma\}_{3}, \ldots,\{\sigma\}_{N}\right\}$

for $X^{i}$ [14]. From this finite set of solutions, the expected values of displacement and stress are computed using the following formulas;

$\mu_{\left\{q_{\beta}\right\}}=\frac{1}{N} \sum_{i=1}^{N}\left\{q_{\beta}\right\}_{i}$

(1)

$$
\mu_{\{\sigma\}}=\frac{1}{N} \sum_{i=1}^{N}\{\sigma\}_{i}
$$

\section{Numerical Example}

Variations in material and geometrical properties and capacity of connections affect the uncertainty in structural response of steel-concrete composite systems. Therefore, the attentions should be focused to compare the stochastic dynamic responses of structural systems made of composite crosssections for different random variables. An eight-story composite residential building was considered in this study. A typical floor plan is shown in Fig.1. The composite residential building has 8 stories and typical floor height is $3.0 \mathrm{~m}$. Framing of the building is irregular in plan where there are 7 axes in X-direction and 3 axes in Y-direction. In order to study the stochastic dynamic response of the steel-concrete composite beam and column with type PR connections shown in Fig. 2, the elastic module of the material characteristic, E and the connection stiffness $\mathrm{k}$ are modelled as random variables. The composite columns (Fig. 2c) and composite beams (Fig. 2d) are consisting of a concrete part $(\mathrm{Ec}=$ $3.0 \times 107 \mathrm{kPa}, \mathrm{Gc}=1.25 \times 107 \mathrm{kPa}, \rho_{c}=2500 \mathrm{~kg} / \mathrm{m}^{3}$ $v=0.20$ ) stiffened by a steel one (Es $=2.1 \times 108 \mathrm{kPa}, \mathrm{Gs}=$ $8.75 \times 107 \mathrm{kPa}, \rho_{s}=7850 \mathrm{~kg} / \mathrm{m}^{3}$ ) (reference material). The column has a box shaped closed composite cross section as shown in Fig. 2c. The cross-section properties are computed as $\mathrm{AE}=\mathrm{AG}=0.0251 \mathrm{~m} 2$, Iy $=5.364 \times 10-4 \mathrm{~m} 4, \mathrm{Iz}=$ $1.986 \times 10-4 \mathrm{~m} 4$, It $=8.295 \times 10-4 \mathrm{~m} 4$. The composite beams are formed as a box shaped composite cross section, with uniform Poisson's ratio $v=0.20$ and damping ratios $\xi=0.05$. The cross-section properties is computed as $\mathrm{AE}$ $=\mathrm{AG}=0.147 \mathrm{~m}^{2}, \mathrm{Iy}=0.0014 \mathrm{~m} 4, \mathrm{Iz}=0.0064 \mathrm{~m} 4, \mathrm{It}=0.063$ $\mathrm{m} 4$ (Fig. 2d). The shear deformation coefficient for two sections is selected as $\mathrm{ay}=\mathrm{az}=0$.

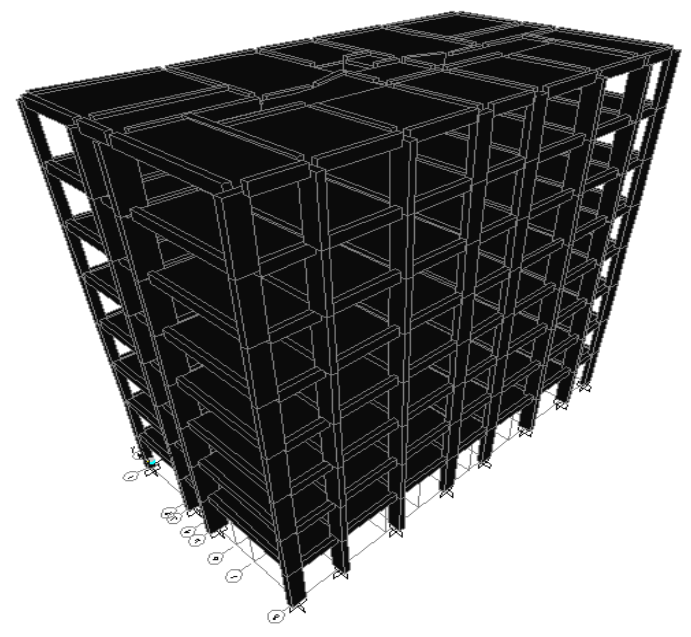

Figure 1.Three dimensional finite element model of building

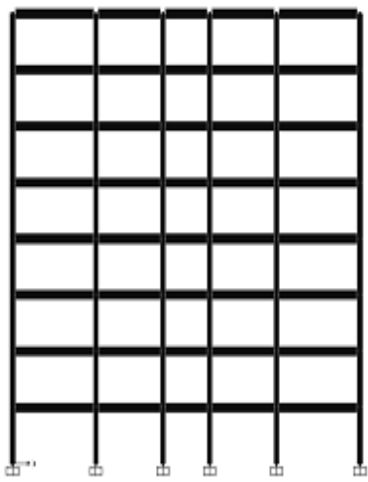

(a)

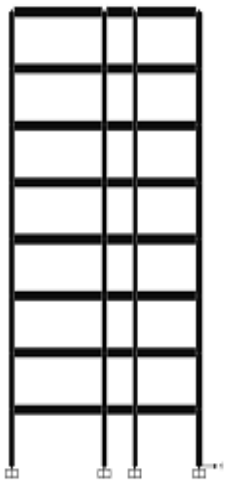

(b)

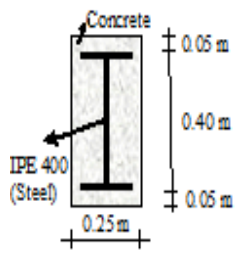

(c)

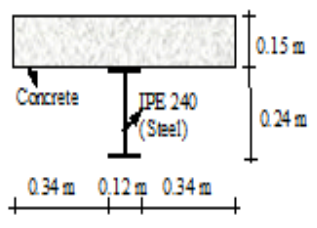

(d)
Figure 2. (a) Typical X-Z sectional view (b) Typical Y-Z sectional view (c) The dimensions of composite column crosssection. (d) The dimensions of composite beam cross-section.

The probability density function of random variables is assumed as normal (or Gaussian) distribution. The Mode Superposition Method considering the Wilson- $\Theta$ algorithm is used for solving the dynamic equilibrium equations. 1999 Kocaeli earthquake is the largest natural disasters of the 20th century in Turkey after 1939 Erzincan earthquake. For the Kocaeli earthquake, the official death toll was more than 15 000, with approximately 44000 people injured and thousands left homeless. For that reason, YPT330 component of Yarimca station records of 1999 Kocaeli Earthquake (Fig. 3) is utilized as ground motion [15]. This ground motion continued up $35.0 \mathrm{~s}$ is applied to the system in a horizontal direction. The dynamic responses of the composite structure are obtained for a time interval of $0.005 \mathrm{~s}$. The composite residential building is modeled by equal lengths of 1840 stochastic finite elements. MCS method was simulated for 
10000 simulations. Mean of maximum displacements and internal forces are determined according to PSFEM and MCS method for composite system. The stochastic finite element results obtained from Case A, Case B are compared with each other.

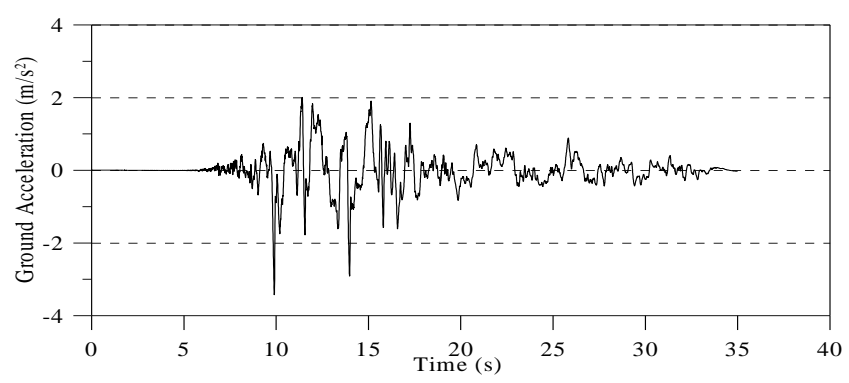

Figure 3. Acceleration time history of Kocaeli earthquake (YPT330), 1999 [15].

Case A. Elastic module of material properties is chosen as random variable for composite structure. The other variables are considered as deterministic for steel-concrete composite system. The elastic module of composite elements is chosen as reference material's (steel) elastic module. This random variable is assumed to follow a normal distribution with the coefficient of variation 0.15 . The respective expectation and correlation function and coefficient of variation [1] for the elastic modulus $E_{\rho}$ are assumed as follows:

$E[E \rho]=2.1 \times 108 \mathrm{kPa} \quad \lambda=10$

$\mu\left(E_{\rho}, E_{\sigma}\right)=\exp \left(-\frac{\left|x_{\rho}-x_{\sigma}\right|}{\lambda l}\right) \quad \rho, \sigma=1,2, \ldots, 72$

$\alpha=0.15$

where $x_{\rho}, l$ and $\lambda$ are ordinates of the element midpoints (n random variable, $\rho, \sigma=1,2, \ldots, n$ ), structural member length and decay factor.

Case B. The variation in connection rigidity, k, was modeled as random variables for steel-concrete composite structure. Different approaches in literature are used to model the connection. This study includes representing the connection by a rotational spring attached to each end of the connecting member. A non-dimensional fixity factor is used to characterize the connection behavior. Two types of semi-rigid beam-to-column connections were considered. The first of these connections is relatively stiff $\left(\mathrm{k}_{1}\right)$ and the second is rather weak $\left(\mathrm{k}_{2}\right)$. For comparison, the same structure with rigid joints $\left(\mathrm{k}_{0}\right)$ was analyzed.

The respective expectation and correlation function and coefficient of variation for the connection rigidity $k \rho$ are assumed as follows:
E1 $\left[\mathrm{k}_{1}\right]=1013796 \mathrm{kNm} / \mathrm{rad}$
$\lambda=10$
E2 $\left[\mathrm{k}_{2}\right]=337932 \mathrm{kNm} / \mathrm{rad}$
$\lambda=10$

$$
\mu\left(E_{\rho}, E_{\sigma}\right)=\exp \left(-\frac{\left|x_{\rho}-x_{\sigma}\right|}{\lambda l}\right) \quad \rho, \sigma=1,2, \ldots, 72
$$

$\alpha=0.15$

\subsection{Responses of Composite structure with PR Connections}

The composite structure is assumed to be subjected to the ground motion shown in Fig. 2. The stochastic finite element analysis of the composite structure with various connection types according to random connection stiffness, material and geometrical properties has been carried out. Characteristic results of the lateral displacements along story height of composite structure as well as bending moments, shear forces and axial forces at the base of the columns for the various types of connections are presented.

\subsubsection{Horizontal Displacements}

Firstly, the accuracy of PSFEM is tested with MCS method. For this aim, these two methods are compared with each other for the horizontal displacement values (Fig. 4) and other internal forces (shear forces, bending moment and axial forces) are given for only PSFEM.

The mean of maximum horizontal displacements along the right border of composite system according to PSFEM and MCS methods are presented in Fig. 4 for Cases A-B. The overall horizontal displacements values according to PSFEM of composite structure subjected to ground motion are greater than those of the MCS method for all random variables. However, the displacement values obtained from the perturbation method are generally close to those calculated using MCS method, as shown in Fig. 4. At the top of composite system where maximum horizontal displacement takes place, it can be observed that the maximum differences between PSFEM and MCS method are 5.5\% and 4.4\%, respectively for Cases A-B.

It can be seen from Fig. 4 that the structure with PR connections has a greater lateral displacement than the other one with fully rigid connection. These differences increase with decrease in the connection stiffness.

\subsubsection{Internal Forces}

The maximum shear forces at the top joint of columns in every floor for the residential composite structure are plotted in Fig. 5 for Cases A-B. It is seen from Fig. 5 that the composite structure with PR connections has a smaller shear forces $(\mathrm{k} 1)$ when compared with the fully rigid connection (k0). These differences increase with decrease in the connection stiffness. The maximum differences between $\mathrm{k} 0$ and $\mathrm{k} 2$ according to $\mathrm{k} 1$ connections in the shear forces at the base of the composite structure with rigid joints and PR type of joints are $19.3 \%$ and $8.6 \%$ for Cases A-B, respectively. Changes in the bending moments are similar to shear forces for full rigidity and PR connections of Cases A-B (Fig. 6).

The last comparison for internal forces is about axial forces obtained from this structural system. Fig. 7 presents maximum axial forces of the columns in every floor for the structure. It can be seen from Fig. 7 that the composite structure with type PR connections has smaller axial forces when compared with the fully rigid connection.

These differences increase with decrease in the connection stiffness. Consequently, the difference in maximum axial 
force at the column of the composite system with rigid joints (k0) and PR type of joints $\left(\mathrm{k}_{1}\right)$ are $48.5 \%$ and $11.9 \%$ for Case $\mathrm{A}$, and $49.9 \%$ and $10.5 \%$ for Case $\mathrm{B}$ according to $\mathrm{k}_{2}$, respectively

It is obvious that there is a significant difference between the results obtained for the composite structures with rigid joints $\left(\mathrm{k}_{0}\right)$ and the structures with PR $\left(\mathrm{k}_{1}\right.$ and $\left.\mathrm{k}_{2}\right)$ connections especially in the case of the weak connections types $\left(\mathrm{k}_{2}\right)$.

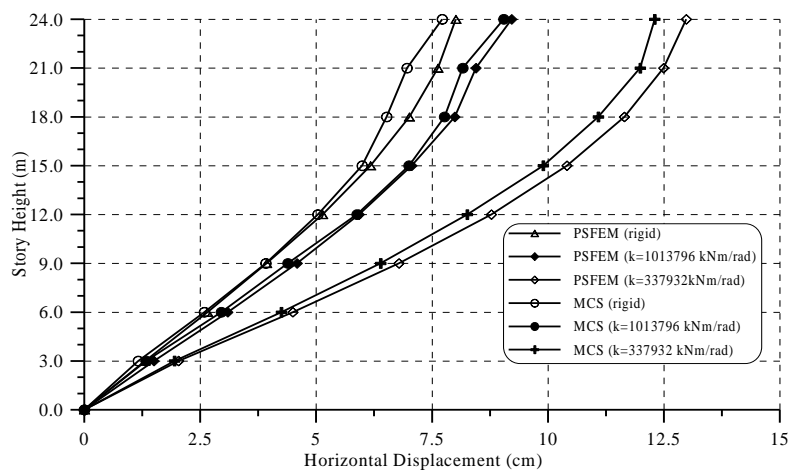

(a)

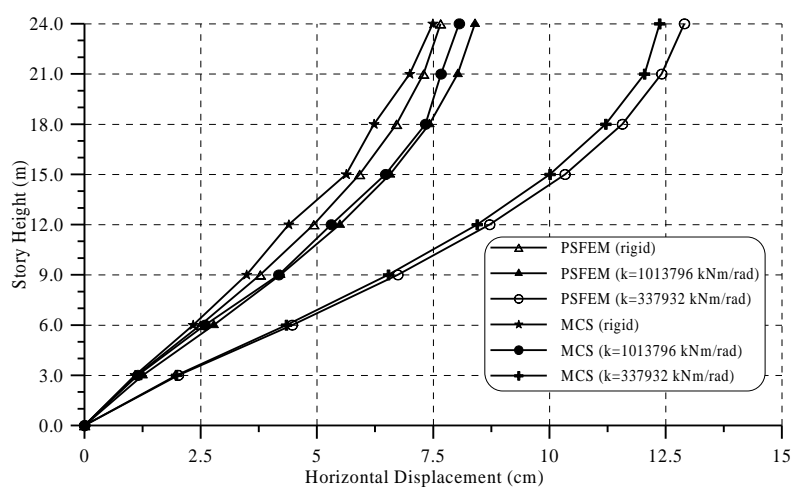

(b)

Figure 4. Mean of maximum horizontal displacement along the story height of the composite structure for Case A (a), Case B (b).

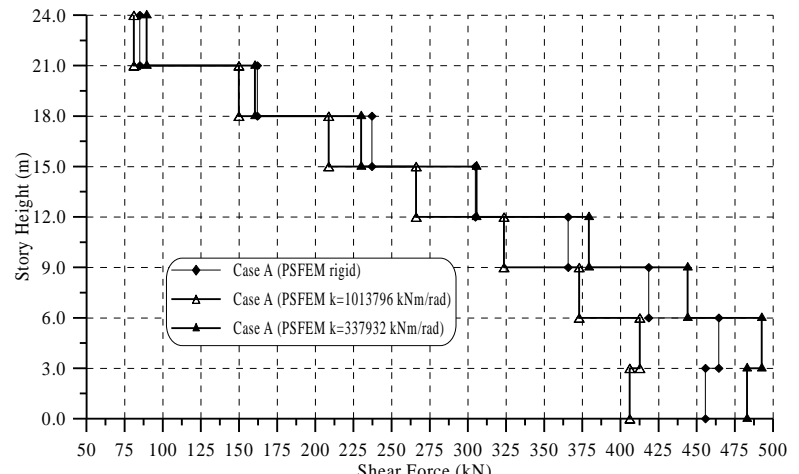

(a)

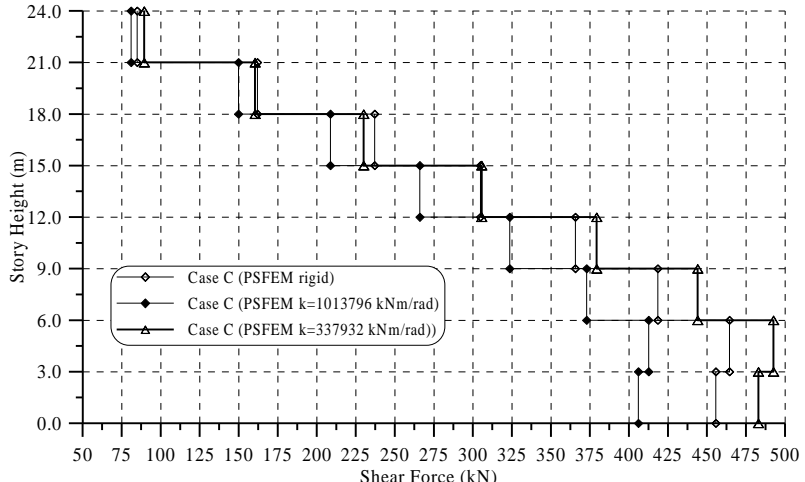

(b)

Figure 5. Mean of maximum shear forces at the top joint of the columns along the story height of the composite structure for Case A (a), Case B (b)

\subsubsection{Limitation in the PSFEM}

The horizontal displacements determined by PSFEM and by MCS method were compared for 0.05. The maximum horizontal displacements at top of the composite structure are given in Figs. 8(a) and (b). These figures show that the differences between maximum displacements obtained from PSFEM and MCS remains acceptable level if $\alpha$ is less than 0.20 .

If it is mentioned the results obtained from this example; for the analysis of this composite structure (Fig. 1-2) presented its numerical properties, it needs about twenty seconds for perturbation based stochastic analysis, however, it needs about fourteen hours for MCS analysis with the PC which have Intel Pentium (R) $2.40 \mathrm{GHz}$ CPU and $768 \mathrm{MB}$ RAM.

The accuracy of the obtained results compared with those acquired from MCS method solution is remarkable. However, as the number of degrees of freedom of the structure and the number of uncertain parameters increase, the structural analyses based on MCS becomes very heavy from a computational point of view, and, in some cases, the computational effort makes them inapplicable.

It can be seen from these figures that the maximum values of dynamic responses from the three random variables are very similar to the result from the MCS method. For accurate dynamic responses, it is necessary that the analysis technique incorporate the effect of structural parameter randomness. This is of special importance for accurate stochastic dynamic analysis of composite systems, which exhibit wide dispersion in structural parameters. 


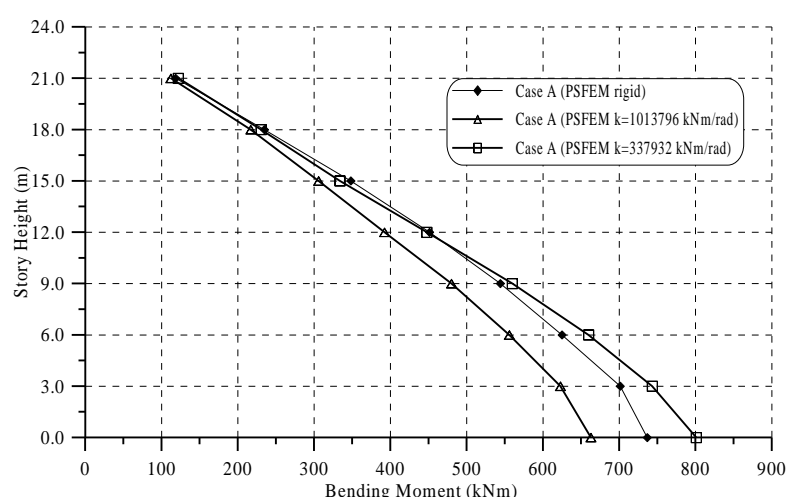

(a)

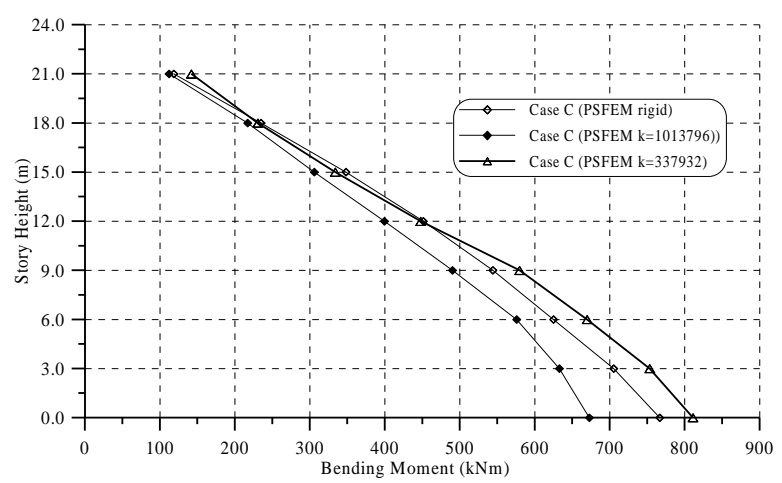

(b)

Figure 6. Mean of maximum bending moment at the top joint of the columns along the story height of the composite structure for Case A (a), , Case B (b).

\section{CONCLUSIONS}

In this paper, the effect of variability in elastic module and initial connection stiffness on the stochastic responses of the composite structure with type PR connections subjected to ground motion is investigated using PSFEM and MCS method. The complex dynamic stiffness matrix for a prismatic composite beam with rotational springs at its ends was obtained in an explicit form. The stiffness matrix was based on the analytical solutions for stochastic finite element analysis of steel-concrete composite 3-D frame with type PR connections and some conclusions are drawn for the systems as follows:

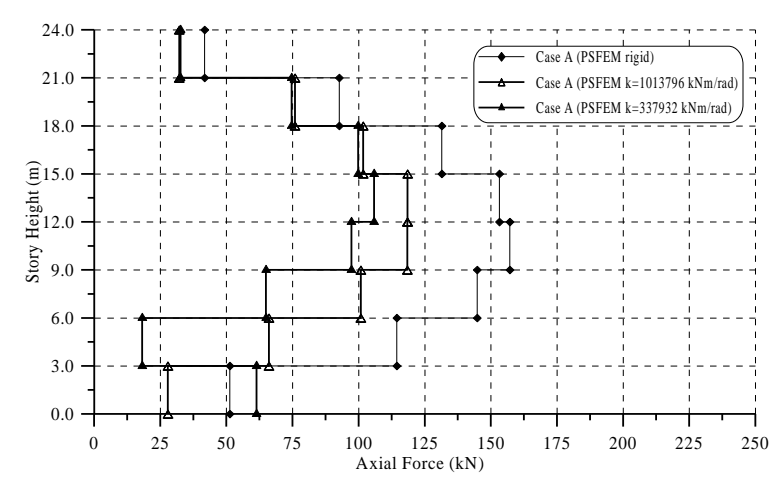

(a)

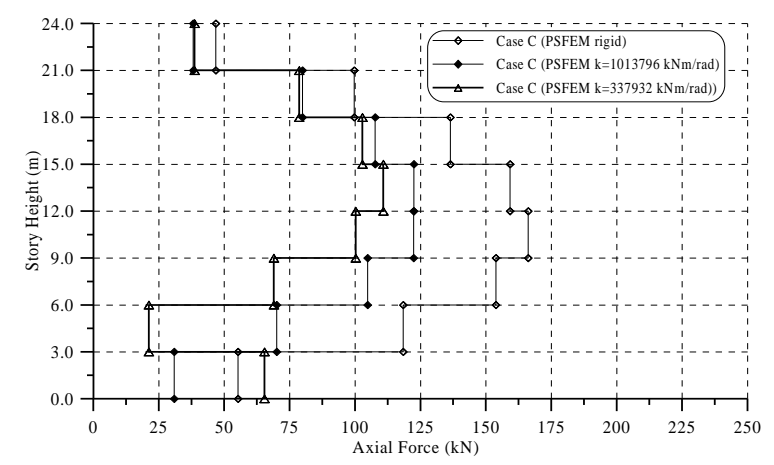

(b)

Figure 7. Mean of maximum axial force at the top joint of the columns along the story height of the composite structure for Case A (a), Case B (b).

On the bases of the above theoretical considerations and the results of the applied numerical analysis, it is evident that the PR connections greatly influence the dynamic behavior of steel-concrete composite structure. The connection flexibility may significantly alter the response of structure.

From the results of numerical example, it can be concluded that the stochastic structural responses of the composite structure with PR connections and the composite structure with conventional type of connections (rigid) are considerably different. It shows that the stochastic effect of PR connections on structural response is significant. Therefore, the stochastic variation of PR connections should be used in design and response analysis of real composite structures.

These numerical conclusions show that displacements and internal forces are close to all random variables (elastic module and connection stiffness) for PSFEM and MCS method. The stochastic finite element response values obtained for the random variable connection stiffness are generally higher than those of the other random variables for chosen composite structure.

The connections are vital structural components that are very often responsible for the behavior and safety of structures subjected to strong dynamic (seismic) loads. Overestimating the connection restraint can result in larger lateral displacements than what was predicted. Therefore, connection design and modeling have a great practical importance. 


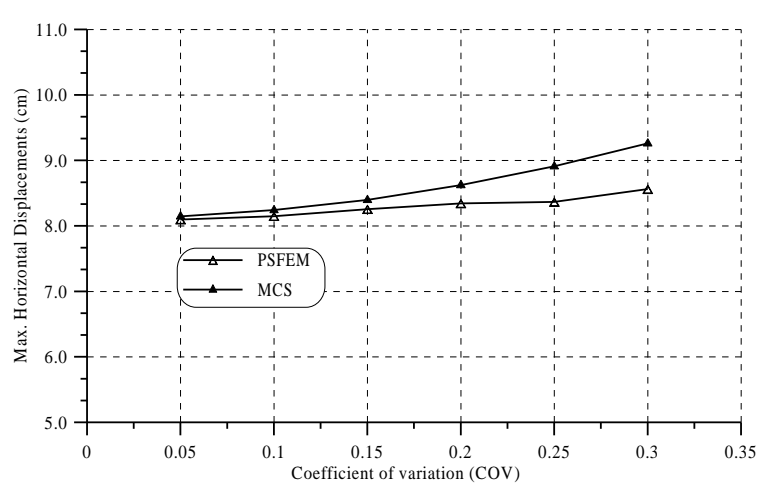

(a)

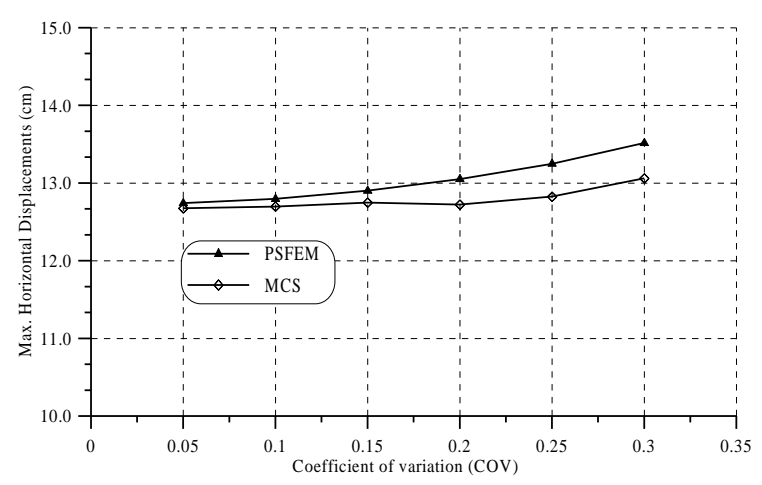

(b)

Figure 8. Comparison of the PSFEM with MCS method for composite structure with PR connection (a) $\mathrm{k}_{1}=1013796 \mathrm{kNm} / \mathrm{rad}$ (b) $\mathrm{k}_{2}=337932 \mathrm{kNm} / \mathrm{rad}$.

\section{REFERENCES}

[1] Kleiber, M. and Hien, T., 1992. The stochastic finite element method. John Wiley and Sons, New York, USA.

[2] Leon, R.T, 1998 "Analysis and design problems for PR composite flames subjected to seismic loads" Engineering Structures, 20 (4-6), 364-371.

[3] Wang, J.F., and Li, G.Q., 2008 "A practical design method for semi-rigid composite frames under vertical loads" Journal of Constructional Steel Research, 64, 176-189.

[4] Vellasco, P.C.G.D., de Andrade, S.A.L., da Silva, J.G.S., de Lima, L.R.O., and Brito, O., 2006 "A Parametric Analysis of Steel and Composite Portal Frames with Semi-Rigid Connections" Engineering Structures, 28(4), 543-556.

[5] Fang, L.X., Chan, S.L., and Wong, Y.L., 1999 "Strength Analysis of Semi-Rigid Steel-Concrete Composite Frames" Journal of Constructional Steel Research, 52 (3), 269-291.

[6] Sekulovic, M., Salatic, R., Nefovska, M., 2002 "Dynamic analysis of steel frames with flexible connections", Computers and Structures, 80, 935-955.

[7] Dissanayake, U.I., Davison, J.B., and Burgess, I.W., (1999) "Composite beam behaviour in braced frames", Journal of Constructional Steel Research, 49, 271-289.

[8] Gao, L., and Haldar, A., (1995) "Safety evaluation of frames with PR connections", Journal of Structural Engineering, 121(7), 1101-1118.

[9] Sakurai, S., Ellingwood, B.R. and Kushiyama, S., 2001 "Probabilistic study of the behavior of steel frames with partially restrained connections", Engineering Structures, 23, 1410-1417.

[10] Çavdar, Ö. (2009), The determination of seismic behavior of the systems connected semi rigidly and constituted of composite sections with stochastic finite element method, Ph.D. Thesis, Karadeniz Technical University, Trabzon, Turkey, (in Turkish).

[11] McGuire, W., Gallagher, R.H. and Ziemian, R.D. (1999). Matrix Structural Analysis, 2nd ed., John Wiley \& Sons, Inc., USA.

[12] Pilkey, W.D., 2002. Analysis and Design of Elastic Beams-Computational Methods, Wiley, New York.

[13] Shinozuka, M. (1972), "Monte Carlo Simulation of structural dynamics", Computers \& Structures, 2(5-6), 865-874.

[14] PEER (Pacific Earthquake Engineering Research Centre), http://peer.berkeley.edu/smcat/data, 2019. 